\title{
Recurrent Pterygium Excision with Extended Resection and Limbal Conjunctival Autograft - Our Results
}

\author{
Shreesha Kumar Kodavoor, ${ }^{1}$, Preethi Venkatesh ${ }^{1}$, Ramamurthy Dandapani ${ }^{2}$, \\ Gitansha Shreyas Sachdev ${ }^{2}$ \\ ${ }^{1}$ Department of Cornea and Phacorefractive, The Eye Foundation, Coimbatore, India \\ ${ }^{2}$ Department of Cataract and Refractive, The Eye Foundation, Coimbatore, India \\ Email address: \\ eskay_03@rediffmail.com (S. K. Kodavoor), preethi.vee.31@gmail.com (P. Venkatesh), \\ drramamurthy@theeyefoundation.com (R. Dandapani), gitansha@theeyefoundation.com (G. S. Sachdev) \\ ${ }^{*}$ Corresponding author
}

\section{To cite this article:}

Shreesha Kumar Kodavoor, Preethi Venkatesh, Ramamurthy Dandapani, Gitansha Shreyas Sachdev. Recurrent Pterygium Excision with Extended Resection and Limbal Conjunctival Autograft - Our Results. International Journal of Ophthalmology \& Visual Science.

Vol. 6, No. 2, 2021, pp. 67-71. doi: 10.11648/j.ijovs.20210602.11

Received: March 8, 2021; Accepted: March 26, 2021; Published: April 7, 2021

\begin{abstract}
Aim: To analyze the recurrence rates and complications after extended resection and limbal conjunctival autograft in recurrent pterygium cases. Materials and methods: Retrospective analysis of 216 eyes of 214 patients was done. All the surgeries were performed under subconjuctival infiltrative anaesthesia. Extensive excision of the pterygium was done along with $1 \mathrm{~mm}$ of normal conjunctival tissue all around and the tenons was resected all around behind and beyond the excised conjunctival margins. A large conjunctival autograft with a thin block limbal tissue in the graft was taken from the superior conjunctiva and placed on the bare sclera with proper orientation (limbal end towards the cornea) and was fixed with fibrin glue. In 6 cases the autograft with the limbal tissue was taken from the inferior conjunctiva as the superior conjunctiva was scarred due to previous surgeries No other adjuvants were used during the procedure. Results: Among the 214 patients, 212 patients had unilateral recurrent pterygium and 2 patients had bilateral recurrent pterygium. All the patients were followed up for a minimum of 6 months with an average follow up of 18 months. Recurrence was seen in 6 eyes $(2.7 \%)$, out of which 2 eyes had one recurrence earlier, 3 eyes had two recurrences earlier and one eye had three recurrences before. Conclusion: Extended pterygium resection with large limbal conjunctival autograft seems to be an effective surgical procedure in recurrent pterygium with less recurrence and encouraging results.
\end{abstract}

Keywords: Recurrent Pterygium, Limbal Conjunctival Autograft, Extended Resection, Recurence

\section{Introduction}

Pterygium is a fibrovascular, wing shaped tissue seen in the bulbar conjunctiva, which encroaches the cornea. It is one of the commonly seen ocular surface disorders. Though multifactorial causes have been suggested in the etiopathogenesis of pterygium, UV light is still the most important etiological factor. [1-3] Recurrence of pterygium after its surgical excision is a frustrating cause of concern for both the surgeon and the patient. Various techniques have been described but, all have their own merits and limitations. The main objective of all the techniques is to prevent the recurrence of the pterygium. Since the recurrent pterygia are more aggressive it is of utmost importance that extensive resections of the pterygium should be carried out to prevent the second recurrence. The concept of including limbus to prevent recurrence has now been emphasised as limbal tissue acts as a barrier to conjunctival growth. [4-6] In this study we have combined two surgical methods for pterygium treatment, that is extensive pterygium resection combined with limbal conjunctival autograft to obtain better outcomes.

\section{Materials and Methods}

Patients presenting to tertiary eye centre in the southern part of India with recurrent pterygium who had undergone extensive pterygium excision with extended resection and 
large limbal conjunctival autograft were included in the study. Retrospective analyses of the patients was done. Data regarding patient's age, sex, ocular, medical, and surgical history, visual acuity before and after surgery, surgical technique, and complications were collected. A total of 216 eyes and 214 patients were included in the study. Slit lamp examination was done before the surgery and the extent of pterygium was noted and were graded [Grade 1: Normal appearance of the operated area; Grade 2: Presence of episcleral vessels in the excised area extending to the limbus, without any fibrous tissue; Grade 3: Fibrovascular tissue in the excised area reaching the limbus, not the cornea (conjunctival recurrence), Grade 4: True corneal recurrence with fibrovascular tissue on the cornea]. The superior conjunctiva was examined for scarring and fibrosis before the procedure. None of the patients had symblepharon.

Among the 214 patients, 212 patients had unilateral recurrent pterygium and 2 patients had bilateral recurrent pterygium. The male: female ratio was 94:120. The follow up period ranged from 6-42 months with an average follow up of 18 months. In 177 eyes recurrence occurred for the first time, 34 eyes had a recurrence for the second time and 5 eyes had their third recurrence. All the surgical procedure was performed by a single surgeon and study protocol adhered to the tenets of the Declaration of Helsinki. The study was approved by the institutional ethics committee and all participants signed written informed consent.

\section{Surgical Procedure}

All the surgeries were performed under topical and infiltrative anaesthesia. Topical $0.5 \%$ proparacaine HCL (Aurocaine, Aurolab, India) was used. Approximately about 1 cc of $2 \%$ xylocaine (AstraZeneca, UK) was injected subconjunctivally into the pterygium tissue before starting the excision. Both blunt and sharp dissection was carried out to detach the corneal attachment of the pterygium and an extensive excision of the pterygium was done along with $1 \mathrm{~mm}$ of normal conjunctival tissue all around (figure 1a). About 0.5 $\mathrm{mm}$ of the tenons was resected all around behind and beyond the excised conjunctival margins (figure 1b). Adherent fibrovascular remnant tissue over the cornea was dissected and the corneal surface was smoothened with a crescent blade. The bare scleral area was measured and superotemporal conjunctiva dissected. Adequate care was taken during the autograft dissection to obtain a thin graft without disturbing the underlying tenons. On reaching the limbus a thin block of corneal tissue, about $0.5 \mathrm{~mm}$ onto the cornea and approximately $100 \mu$ thickness was dissected with the use of cresent blade and was included in the autograft (figure 1c). A large conjunctival autograft with limbal stem cells (figure 1e), was placed on the bare sclera with proper orientation (limbal end towards the cornea), and was fixed with fibrin glue (Tisseel, Baxter, Vienna, Austria). No other adjuvants were used during the procedure. In 6 cases the autograft was taken from the inferior conjunctiva as the superior conjunctiva was scarred due to previous surgeries. No intraoperative complications were noted. Post-operatively all the patients were started on topical antibiotics (0.5\% Moxifloxacin) 4 times a day for 2 weeks, topical steroids $(0.5 \%$ Loteprednol) for 6 weeks, and preservative free tear substitutes $(0.5 \%$ Carboxy methyl cellulose) for 6 weeks. The patients were followed up on post-operative day 1, 2 weeks, 6 weeks and 6 months and every 6 months thereafter.

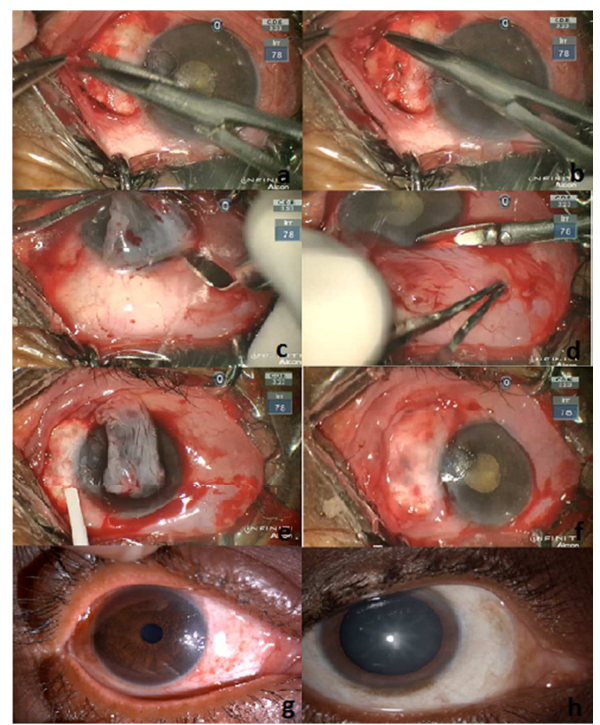

Figure 1. 1a. Extended excision of the recurrent pterygium, 1b. resection of the tenons beyond the normal conjunctival margins, 1c. Dissection of the thin block of corneal tissue, 1d. Dis insertion of the limbal conjunctival autograft after its dissection., 1e. Instillation of the fibrin glue over the bare sclera, 1f. The limbal autograft placed over the bare sclera with proper orientation of the limbal cells towards the cornea, $1 g$. Post-operative picture after 2 weeks, 1 h. 3 months post-operatively.

The outcome measures like recurrence, graft edema, graft retraction, graft loss, and other complications were noted in each follow up. Recurrence being the main outcome measure was defined as fibrovascular tissue growth of $1.5 \mathrm{~mm}$ or more beyond the limbus onto the clear cornea with conjunctival dragging as described by Singh et al. [7] Conjunctival recurrence was not included.

\section{Results}

A total of 216 eyes was included in the study. All the patients were followed up for a minimum of 6 months with an average follow up of 18 months. Immediate complications like sub-conjunctival hemorrhage were seen in 151 eyes $(69.9 \%)$, graft edema in 156 eyes $(72.2 \%)$, and retraction of the graft (figure 2c) was seen in 50 eyes (23.14\%). No additional medications or intervention was done in these cases. Recurrence was seen in 6 eyes $(2.7 \%)$, out of which 2 eyes had one recurrence earlier, 3 eyes had two recurrences earlier and one eye had three recurrences before. Conjunctival recurrence was seen in 4 eyes. Graft loss was seen in 6 eyes of which 5 had recurrence later. Donor site complications like granuloma (figure $2 b$ ) were seen in 4 eyes and 2 eyes had vascularization. Granuloma was also seen in the host area (figure 2d) in 4 eyes. Severe corneal scarring 
(figure 2a) occurred in 4 eyes. Dellen was noticed in 3 eyes which returned to normal with the lubricating drops. Table 1 shows a list of complications noted after the procedure.

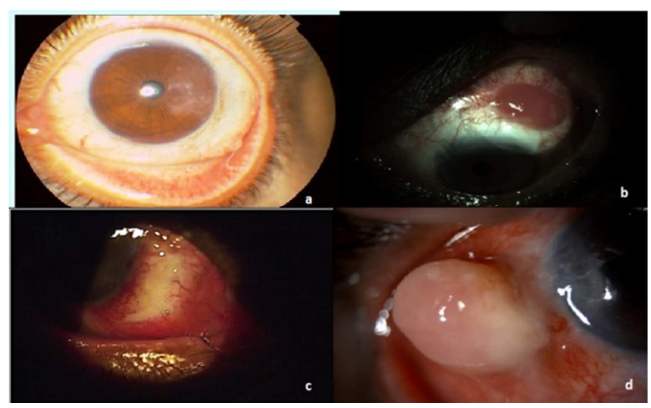

Figure 2. 2a: Corneal scar after pterygium excision, 2b. Granuloma at the donor site, 2c. Graft retraction., 2d. Granuloma at the graft area.

Table 1. List of complications which were noted post-surgery in our study.

\begin{tabular}{lll}
\hline Complication & No eyes $(\mathbf{n}=\mathbf{2 1 6})$ & percentage \\
\hline Sub conjunctival haemorrhage & 151 & $69.9 \%$ \\
Graft edema & 156 & $72.2 \%$ \\
Graft retraction & 50 & $23.14 \%$ \\
Recurrence & 6 & $2.7 \%$ \\
Granuloma & & \\
Donor site & 4 & $1.9 \%$ \\
Host site & 4 & $1.9 \%$ \\
\hline
\end{tabular}

\section{Discussion}

Recurrent pterygia have an aggressive growth pattern. They tend to cause significant conjunctival inflammation and may also cause symblepharon which in turn causes restriction in eye movements. The other complications seen with recurrent pterygium are corneal scarring, limbal stem cell deficiency. All the features mentioned above make the surgical excision of the recurrent pterygium difficult and have an increased predisposition for failure. Hence the main aim of any surgical method followed is to reduce the recurrence. Commonly followed surgeries include pterygium excision with conjunctival autograft [8-10], pterygium excision with mitomycin application, [11, 12] amniotic membrane with limbal autograft in advance pterygium cases [13-15] and also P. E. R. F. E. C. T (Pterygium Extended Removal Followed by Extended Conjunctival Transplant) technique described by Lawerence Hirst. [16, 17]

In the P. E. R. F. E. C. T technique, the pterygium was transected with extensive removal of the conjunctiva was done, approximately extending from superior to inferior recti and up to the caruncle medially. A large conjunctival defect of about $8 \mathrm{~mm}$ at the limbus, $15 \mathrm{~mm}$ horizontally, and $12 \mathrm{~mm}$ vertically was dissected. Similarly, the undermining tenons were dissected below the conjunctival margins. The large defect was closed with a large superior conjunctival graft leaving behind $1.5-2 \mathrm{~mm}$ of the limbal conjunctival at the donor site. In our study, we did an extensive pterygium excision by resecting the fibrovascular tissue in all quadrants including $1 \mathrm{~mm}$ of the normal conjunctiva. The tenons was also resected $0.5 \mathrm{~mm}$ behind and beyond the cut conjunctival margins, but too extensive conjunctival resection was avoided.

The limbal epithelium is thought to function as a barrier in preventing the conjunctival epithelium growth over the cornea. Dushku e al [4] emphasized on the function of the limbal cell and altered limbal cells were also noticed in the pterygium cases. It is been noted that a plane conjunctival autograft has high recurrence rates in comparison to limbal graft when done for recurrent pterygium. In a study done by Malik et al showed a recurrence rate of $2.5 \%$, [18] a similar recurrence rate was reported in Master et al study which was $2.14 \%$. [19] A study done by Fayerz et al reported a lesser recurrence rate of $1 \%$ with limbal autograft. [20] In our study after extended pterygium excision, we included limbal tissue with the conjunctival autograft to further decrease the rates of recurrence. recurrence. Considering the number of cases which had more than one earlier recurrence, our technique has given excellent result. Other procedures like amniotic membrane graft, MM-C, lamellar keratoplasty have been stated for recurrent pterygia. Comparison of the outcomes of other procedures with that of our study is been illustrated in table 3 . The recurrence rates are considerably less with limbal conjunctival autograft.

Table 2. Comparision of our study results with P. E. R. F. E. C. T ((Pterygium Extended Removal Followed by Extended Conjunctival Transplant).

\begin{tabular}{lllll}
\hline Author & Number of eyes & Mean follow up & Recurrence & Other complications \\
\hline Our study & 216 & 18 months & $6(2.7 \%)$ & SCH, graft edema, Graft retraction, granuloma \\
Lawrence Hirst [17] & 111 & 18 months & 0 & Pain, SCH Graft edema, dellen Transient diplopia, \\
\hline
\end{tabular}

In this study, we have combined two surgical procedures as mentioned above. Since extensive resection as defined in $\mathrm{P}$. E. R. F. E. C. T is associated with other problems like pain, injury to the medial rectus which leads to diplopia and also very time consuming. Only extended resection about $1 \mathrm{~mm}$ behind the pterygium margins is been done to avoid such complications. Since patients with multiple recurrences were recruited in the study, the limbal tissue with the conjunctival autograft was included. The total recurrence seen in our study was 6 eyes $(2.7 \%)$. The recurrence noted after P. E. R. F. E. C. $\mathrm{T}$ claims to be nil among 111 patients in 1 year follow up. In table 2 outcomes of our study and P. E. R. F. E. C. T has been depicted in brief. We have recruited 216 eyes which is almost double the number of patients with an average follow up of 18 months. $2.7 \%$ of recurrence is quite low in a country with a hot climatic conditions like India. We even included a sizeable number of patients with more than one earlier recurrence. Vasularisation was seen in 2 eyes at the donor site. Granuloma was seen at the donor site in 4 eyes and at the host site in 4 eyes. Nevertheless, the results got from this study prove that the combination of extended pterygium resection with limbal conjunctival autograft is effective and reliable in recurrent pterygium cases. The limitation of this study is that it is a retrospective study and comparison with a 
control group would predict more precisely its effectiveness. The surgical method definitely needs expertise and patience to perform but it is unquestionably less time consuming than the P. E. R. F. E. C. T procedure.

Table 3. List of other surgical procedures which have been done in recurrent pterygium and their corresponding outcomes. (AMG: amniotic membrane graft, CAG: conjunctival autograft, LAT: limbal stem cell tansplant).

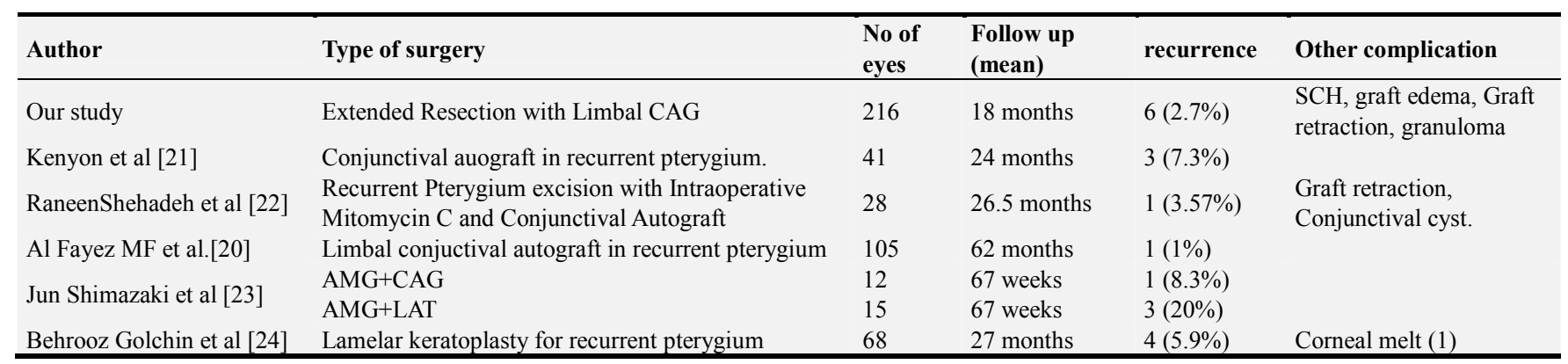

\section{Conclusion}

Recurrent pterygia are difficult in their management. Failure to create a barrier at the limbus may cause further recurrences. Extended pterygium resection with the inclusion of limbal tissue in the conjunctival autograft seems to be an effective surgical procedure in recurrent pterygium, with low recurrence rates. The surgical option is safe with encouraging results. However, a prospective study with long-term follow up may further throw light on its difficulties.

\section{References}

[1] Coroneo MT, Giirolamo ND, Wakefield D (1999) Thepathogenesis of pterygia. Curr Opin Ophtalmol 10: 282-288.

[2] Mackenzie FD, Hirst LW, Battistutta D, Green A (1992) Risk analysis in the development of pterygia. Ophthalmology 99: 1056-1061.

[3] Hilgers JH (1960) Pterygium: its incidence, heredity and etiology. Am J Ophthalmol 50: 635-644.

[4] Dushku N, Reid TW. Immunohistochemical evidence that human pterygia originate from an invasion of vimentinexpressing altered limbal epithelial basal cells. Curr Eye Res 1994; 13: 473-81.

[5] Kwok LS, Coroneo MT. A model for pterygium formation. Cornea 1994; 13: 219-24.

[6] Tseng SCG, Chen JJY, Huang AJW, et al. Classification of conjunctival surgeries for corneal diseases based on stem cell concept. Ophthalmology Clinics of North America 1990; 3: 595-610.

[7] Singh G, Wilson MR, Foster CS. Long-term follow-up study of mitomycin eye drops as adjunctive treatment of pterygia and its comparison with conjunctival autograft transplantation. Cornea 1990; 9: 331-4.

[8] Anduze AL. Conjunctival flaps for pterygium surgery. Annals of Ophthalmology. 2006 Sep; 38 (3): 219-23.

[9] Chua JL and Tan DT: Current concepts and techniques in pterygium treatment. Curr Opin Ophthalmol 18: 308-313, 2007.
[10] Basti S and Rao SK: Current status of limbal conjunctival autograft. Curr Opin Ophthalmol 11: 224-232, 2000

[11] Fakhry MA. The use of mitomycin $\mathrm{C}$ with autologous limbalconjunctival autograft transplantation for management of recurrent pterygium. Clinical Ophthalmology (Auckland, NZ). 2011; 5: 123.

[12] Frucht-Pery J, Ilsar M. The use of low-dose mitomycin C for prevention of recurrent pterygium. Ophthalmology. 1994; 101 (4): 759-762.

[13] Shimazaki J, Shinozaki N, Tsubota K. Transplantation of amniotic membrane and limbal autograft for patients with recurrent pterygium associated with symblepharon. British Journal of Ophthalmology. 1998 Mar 1; 82 (3): 235-40.

[14] Ti SE, Tseng SC. Management of primary and recurrent pterygium using amniotic membrane transplantation. Current opinion in ophthalmology. 2002 Aug 1; 13 (4): 204-12.

[15] Luanratanakorn P, Ratanapakorn T, Suwan-apichon O, Chuck RS. Randomised controlled study of conjunctival autograft versus amniotic membrane graft in pterygium excision. British journal of ophthalmology. 2006 Dec 1; 90 (12): 1476-80.

[16] Hirst LW. Prospective study of primary pterygium surgery using pterygium extended removal followed by extended conjunctival transplantation. Ophthalmology 2008; 115: $1663-72$.

[17] Hirst LW. Recurrent pterygium surgery using pterygium extended removal followed by extended conjunctival transplant: recurrence rate and cosmesis. Ophthalmology. 2009 Jul 1; 116 (7): 1278-86.

[18] Malik KP, Goel R, Gutpa A, Gupta SK, Kamal S, Mallik VK, Singh S (2012) Efficacy of sutureless and glue free limbal conjunctival autograft for primary pterygium surgery. Nepal $\mathrm{J}$ Ophthalmol 4 (2): 230-235.

[19] Masters JS, Harris DJ Jr (2015) Low recurrence rate of pterygium after excision with conjunctival limbal autograft: a retrospective study with long-term follow-up. Cornea 34 (12): $1569-1572$.

[20] Al Fayez MF (2013) Limbal-conjunctival versus conjunctival autograft transplant for recurrent pterygia: a prospective randomized controlled trial. JAMA Ophthalmol 131 (1): 11-16.

[21] kenyon KR, Wagoner MD, Hettinger ME. Conjunctival autograft transplantation for advanced and recurrent pterygium. Ophthalmology. 1985 Nov 1; 92 (11): 1461-70. 
[22] Management of Recurrent Pterygium With Intraoperative Mitomycin $\mathrm{C}$ and Conjunctival Autograft With Fibrin Glue. RaneenShehadeh Mashor Sathish Srinivasan Corey Boimer Kenneth Lee Oren Tomkins Allan R. Slomovic

[23] Shimazaki J, Kosaka K, Shimmura S, Tsubota K. Amniotic membrane transplantation with conjunctival autograft for recurrent pterygium. Ophthalmology. 2003 Jan 1; 110 (1): 119-24.
[24] Golchin B, Butler TK, Robinson LP, Wechsler AW, Sutton G, Robinson DI, McClellan K. Long-term follow-up results of lamellar keratoplasty as a treatment for recurrent pterygium and for scleral necrosis induced by $\beta$-irradiation. Cornea. 2003 Oct 1; 22 (7): 612-8. 